\title{
A Visão Baseada em Recursos na Gestão Pública do Turismo: o caso de Curitiba - PR
}

\section{Resource-Based View to Tourism Public Management: the case of Curitiba - PR}

Márcia Shizue Massukado ${ }^{1}$

Rivanda Meira Teixeira ${ }^{2}$

\begin{abstract}
Resumo
Para analisar os recursos organizacionais e turísticos na gestão pública o presente trabalho escolheu como base teórica a Visão Baseada em Recursos de Barney (1997). Foi realizado um estudo de caso em Curitiba, Paraná; e os dados foram coletados através de entrevistas semiestruturadas com gestores do setor público e do setor privado. As percepções destes dois grupos com relação ao uso dos recursos e o uso de informações documentais permitem inferir que os principais recursos utilizados na implementação de políticas públicas foram os recursos da arquitetura organizacional. Entretanto, o recurso mais importante na gestão pública do turismo, neste município, é a existência de recursos turísticos e institucionais direcionados para os relacionamentos internos e externos.

Palavras-chave: visão baseada em recursos; recursos organizacionais; recursos turísticos; gestão pública do turismo.
\end{abstract}

\begin{abstract}
This study chose as its theoretical framework the Resource-Based View - RBV from Barney (1997) to analyze organizational and tourist resources in the public tourism management. One case study was analyzed: Curitiba, in Paraná State. Data collection was made by adopting semi-structured interviews with managers from public and private sectors. Their perceptions regarding tourist resources and the use of documentary data allow inferring that the main resource utilized in the implementation of public policies was the organizational architecture. However, the most influential resource in public tourism management was the existence of tourist and institutional resources that are orientated to internal and external relationships.
\end{abstract}

Keywords: resource based-view organizational resources; tourist resources; public tourism management.

\section{Introdução}

Dentre os desafios à gestão pública local enumeram-se a geração de emprego, a geração de renda e o crescimento da economia, que permitiriam aos municípios melhorias na qualidade de vida oferecida às suas comunidades. Sendo o turismo, reconhecidamente no Brasil e no

\footnotetext{
${ }^{1}$ Bacharel em Turismo, Mestre em Administração e Doutoranda em Administração pela Universidade Federal do Paraná - UFPR. Professora do Departamento de Turismo da Universidade Federal do Paraná. E-mail massukado@ufpr.br.

2 Doutora em Administração pela Cranfield University na Inglaterra. Pós-doutorado em Turismo na Bournemouth University na Inglaterra e também em Gerenciamento de Pequenas Empresas do Setor Turístico na Strathclyde University, na Escócia. E-mail: rivandateixeira@terra.com.br.
} 
mundo, uma importante atividade geradora de empregos, renda e divisas para as localidades onde se desenvolve, e, sendo essencialmente um serviço que integra diversos setores, o papel da gestão pública destaca-se como um dos vetores responsáveis para a promoção do desenvolvimento sustentável.

Neste tocante é necessário destacar o caráter ambivalente do turismo. Bursztyn (1999 apud EMBRATUR, 2004) ressalta a necessidade de se questionar as conseqüências do turismo como uma atividade econômica. Destaca o autor que o turismo tem enorme potencial de alavancar o desenvolvimento de uma região e, ao mesmo tempo, promover grande degradação ambiental, aliada ao agravamento das injustiças sociais. Esta característica implica, segundo Lee e Barrett (1994), no estabelecimento de políticas e prioridades para a atividade turística e de decisões sobre o nível, tipo e volume de turismo que o país pode suportar, utilizando-se de planejamento, pesquisa e desenvolvimento que enfatizem fatores econômicos, sociais, culturais e ambientais. O estabelecimento de políticas é destinada aos organismos públicos que com a visão abrangente do fenômeno devem estar aptos a realizá-la.

Contudo, o planejamento estratégico voltado para o setor turístico no Brasil ainda se encontra em fase muito preliminar, principalmente no tocante à administração municipal. Até o presente, somente o Governo Federal e alguns Estados, incluindo o Paraná, conseguiram estabelecer de forma palpável políticas destinadas ao incentivo e estruturação da atividade.

Pearce (1998, p. 458-459) destaca a interferência do setor público no turismo afirmando que, por ser um fenômeno multifacetado, tanto o setor privado quanto o público devem ter sua parcela de contribuição para a atividade. Acrescenta que "o setor público, em todos os níveis - nacional, estadual e local - também se envolve no turismo, de maneiras diferentes, seja planejando, provendo infra-estrutura e realimentando a economia ou por razões econômicas, sociais, culturais, ambientais e políticas”. Mas, sem o apoio e a cooperação, somados aos recursos provenientes de outras organizações, o poder público não irá, em geral, obter êxito em dar ao turismo a merecida prioridade econômica. A implementação de políticas torna-se, portanto, um processo de se manter o equilíbrio entre os vários objetivos, e não o de tentar maximizar qualquer um deles isoladamente (LICKORISH; JENKINS, 2000).

Nessa conjuntura, em que se pretende relacionar o turismo a uma atividade sustentável, a articulação de recursos entre os órgãos públicos e privados torna-se um imperativo, devendo ser parte integrante de toda política pública de turismo. Destarte, buscou-se com o estudo em 
pauta, analisar como estão sendo utilizados os recursos organizacionais e os recursos turísticos disponíveis ao setor público para o planejamento e gestão da atividade turística em Curitiba- Paraná, indicando a importância do papel da articulação de recursos para promover o desenvolvimento da localidade como um destino turístico sustentável.

\section{Visão Baseada Em Recursos - Vbr}

A abordagem teórica dos recursos organizacionais apresentada como visão baseada em recursos (ou teoria baseada em recursos) esteve presente, antes de abarcar na arena administrativa - e, principalmente, incorporada a análises e conceituações sobre estratégia -, em trabalhos ligados à teoria econômica. Barney (1996) aponta que a análise dos pontos fortes e fracos da organização e das ameaças e oportunidades do ambiente (SWOT) é descrita em várias tradições de pesquisa, sendo algumas delas disciplinas econômicas. Entre as mais importantes disciplinas que trataram dessa análise, destacam-se as tradicionais pesquisas sobre as competências distintivas das empresas: a economia Ricardiana e a teoria do crescimento da firma de Edith Penrose (1995).

Dentro da área de estratégia organizacional, Mintzberg, Ahlstrand e Lampel (2000) consideram Birger Wernerfelt (1984) como o primeiro a desenvolver as idéias de Penrose, em um artigo premiado que deu nome a teoria baseada em recursos, sendo creditado a Jay Barney o desenvolvimento da visão baseada em recursos, que a transformou em uma teoria completa. Na visão de Carneiro, Cavalcanti e Silva (1999), foi nesta época - final dos anos oitenta - que diversos trabalhos na área da administração estratégica indicaram que as diferenças existentes entre os desempenhos das firmas dentro de uma mesma indústria, mostravam-se expressivamente superiores às diferenças de desempenho entre indústrias, significando que os fatores internos às empresas exerciam um impacto maior em comparação aos fatores externos, isto é, à estrutura da indústria.

Do mesmo modo, Grant (1991) destaca que os estudos em estratégias que focavam os pontos fortes e fracos da empresa foram posteriores ao desenvolvimento dos estudos que enfatizavam a relação entre estratégia e o ambiente externo. Para o autor, o ressurgimento do interesse no papel dos recursos da organização, como base para a estratégia organizacional, foi refletida pela insatisfação com a estrutura equilibrada e estática da economia da organização industrial que dominava o pensamento sobre a estratégia empresarial contemporânea. 
Independente das considerações sobre correntes e origens, Barney (1996) também argumenta que há um recente movimento dessas pesquisas baseadas nos conhecimentos dos gerentes gerais, dos líderes institucionais, das rendas econômicas e do crescimento da empresa para o desenvolvimento de um único, rígido e estruturado modelo que possa ser usado para analisar as fraquezas e os pontos fortes das organizações. É com base nesse modelo geral que o autor inicia o desenvolvimento da teoria a qual atribuiu a denominação de Visão Baseada em Recursos (VBR).

Como a visão da vantagem competitiva examina a relação entre as características organizacionais internas e o desempenho da empresa, a teoria baseada em recursos não poderia ter os mesmos pressupostos adotados pelos estudos que focam na análise das oportunidades e ameaças no ambiente competitivo. Assim, os dois princípios fundamentais da teoria desenvolvida por Barney (1997) foram: (a) o trabalho de Penrose (1995), que explica as empresas podem ser entendidas como conjuntos de recursos produtivos, e que diferentes empresas possuem diferentes conjuntos destes recursos; (b) o trabalho de Selznick (1957) e das economias ricardianas, que explica que alguns recursos organizacionais são ao mesmo tempo muito caros para serem copiados e que possuem fornecimento inelástico, constituindo, neste sentido, a noção da imobilidade dos recursos.

Segundo Barney (1996), o quadro geral da visão baseada em recursos foca na particularidade e nos custos para copiar os recursos controlados pela organização. Isto porque, as organizações dentro de um mesmo setor podem ser heterogêneas no que diz respeito aos recursos estratégicos e, estes recursos, podem não ser perfeitamente móveis entre essas organizações.

Diversos conceitos tratam do significado de recurso organizacional dentro da literatura administrativa. Barney (1996) aponta que um dos primeiros autores a denominar atributos organizacionais utilizando-se da terminologia "recurso" foi Wernerfelt (1984), sendo posteriormente adotado por outros autores. Na construção do conceito de recurso, Barney (1997, p.143), por seu turno, recorre a Daft (1983), afirmando que "os recursos organizacionais são todos os bens, capacidades, competências, processos organizacionais, atributos organizacionais, informação, conhecimento e outros tantos que são controlados pela organização e que possibilitam a empresa conceber e implementar estratégias que aprimorem sua eficiência e eficácia". 
Mais recentemente, Barney (1997) propõe a divisão dos recursos em quatro categorias: (a) recursos financeiros, ou todos os tipos de recursos financeiros que as empresas podem utilizar para conceber e implementar estratégias; (b) recursos físicos, ou capital físico, que correspondem à tecnologia física usada na empresa, a planta organizacional, seus equipamentos, localização geográfica e acesso a matérias primas; (c) recursos de capital humano incluindo o treinamento, experiência, julgamento, inteligência, relacionamentos, bem como os insights dos gerentes e trabalhadores de uma empresa e, (d) recursos institucionais que constituem os atributos da coletividade organizacional - a estrutura organizacional, sistemas de controle e coordenação, a própria cultura da organização, sua reputação, bem como as relações informais entre grupos dentro da própria empresa, ou entre a empresa e seu ambiente.

Grant (1991) apresenta uma proposta diferente de categorização dos recursos que, além dos recursos elencados por Barney (1997), inclui reputação e recursos tecnológicos, ao que denomina de forma ampla de recursos organizacionais. Já Kay (1996) apresenta quatro capacidades diferenciadoras como sendo características importantes do relacionamento de uma organização com outras empresas: (a) a arquitetura organizacional vista como uma rede de contratos em que se podem estabelecer relacionamentos com ou entre seus empregados arquitetura interna -, com seus fornecedores e clientes - arquitetura externa - ou entre um grupo de empresas engajadas em atividades correlatas - redes; (b) a inovação ou capacidade da empresa de oferecer novos produtos ao mercado; (c) a reputação ou mecanismo utilizado para transmitir informações aos consumidores e que se refere a associação que esta faz da organização com os atributos do produto e; (d) os ativos estratégicos que se relacionam ao domínio ou posição da empresa no mercado.

A arquitetura organizacional foi acrescentada a fim de ressaltar a necessidade de parcerias entre as organizações, introduzindo-se o conceito de articulação de recursos como forma de efetivar tais parcerias. Na visão de Mascarenhas e Vasconcelos (2004, p. 08), a teoria dos recursos representou um avanço fundamental nas discussões sobre estratégia das organizações. Os autores acrescentam, ainda, que as teorias de estratégia que partem dessa discussão defendem então que as organizações não devem se preocupar só com o que se fez bem ontem e se faz bem hoje, mas também com o que elas podem fazer bem no futuro. 


\section{Metodologia}

Pretendeu-se, neste estudo, examinar o município turístico de Curitiba analisando de que maneira a teoria de administração estratégica, a Visão Baseada em Recursos - VBR de Barney (1997), pode subsidiar políticas públicas para o desenvolvimento do turismo no município. Especificamente, foram analisados de que forma os recursos organizacionais, os recursos turísticos e a articulação de recursos, junto à iniciativa privada e o setor público, são utilizados pelo órgão municipal de turismo nas políticas públicas voltadas para o desenvolvimento do turismo local.

Nesse contexto, o objetivo do estudo visa compreender a essência dos fenômenos pesquisados, adotando o enfoque indutivo, no qual as idéias são desenvolvidas a partir dos dados coletados da realidade, sob a perspectiva dos gestores públicos e privados que analisam os recursos organizacionais e turísticos envolvidos no processo de desenvolvimento local.

Esse estudo pode ser considerado como exploratório, em função da escassez de estudos sobre o tema no Paraná e também no Brasil. No entanto, pode ainda ser categorizado como descritivo, pois fará a descrição das diversas categorias analíticas identificadas como relevantes. Portanto, a abordagem metodológica utilizada foi a descritivo-qualitativa.

Adotou-se a perspectiva de análise seccional com avaliação longitudinal, tendo em vista que as categorias analíticas foram investigadas ao longo do período compreendido entre 2001 e 2004. O nível de análise é o organizacional, e as unidades de análise são os recursos organizacionais e recursos turísticos utilizados na gestão municipal do turismo, objeto de estudo desta pesquisa. Para este estudo, não houve o estabelecimento de uma amostra probabilística devido ao universo escolhido ser considerado pequeno. Assim, selecionou-se os respondentes a partir do critério de amostragem por adesão.

Os dados secundários referentes aos recursos organizacionais, aos recursos turísticos, às políticas públicas e à articulação de recursos foram coletados em documentos de "primeira mão", ou seja, documentos que não receberam nenhum tipo de tratamento analítico (GIL, 1991, p. 51), como, por exemplo, os documentos conservados nos arquivos dos órgãos públicos e das associações empresariais. Além disso, foram utilizados documentos de segunda mão, que já foram analisados de alguma forma como relatórios de pesquisas, planos e programas, entre outros. A partir da análise dos dados coletados, foi possível a elaboração 
de um roteiro de entrevista semi-estruturada (focal), que foi utilizado como instrumento de coleta de dados de fonte primária.

Os dados primários foram coletados através de entrevistas semi-estruturadas que foram realizadas utilizando-se roteiros de entrevistas que foram aplicados aos representantes dos órgãos competentes de turismo do município, aos representantes do setor privado (associações empresariais) e aos representantes de outros órgãos públicos (municipal, estadual e federal). Em Curitiba foram entrevistados cinco gestores municipais, dois gestores de órgãos públicos estaduais e oito dirigentes do setor privado, totalizando quinze entrevistas.

\section{O Caso de Curitiba}

Curitiba como cidade turística é uma criação; uma união de várias idéias que tinham o objetivo de promover bem-estar e qualidade de vida a seus moradores e que depois originaram atrativos que despertam, até hoje, a curiosidade dos turistas. Nos últimos anos, outros fatores adicionaram-se aos já contemplados atrativos históricos e culturais da cidade, redirecionando a atividade turística local. Desde 2001 o crescimento do fluxo turístico da cidade é acompanhado pelo incremento percentual de turistas que tem como principal motivo de viagem a realização de negócios na capital, que representam, segundo o Fórum para o Turismo Sustentável no Paraná (2004), quase $40 \%$ do total de visitantes que desembarcam na cidade .

A Curitiba analisada neste estudo de caso é uma captura do cenário político e administrativo do turismo da cidade nos últimos quatro anos. Esse panorama tem no vértice um órgão municipal de turismo, subordinado a uma companhia de desenvolvimento e, no trade, em uma profícua visão de consolidação do turismo de negócios e eventos. A administração do turismo em Curitiba, na gestão 2001/2004, era de competência da Companhia de Desenvolvimento de Curitiba - CIC. Dentro da estrutura organizacional da CIC, as atividades relacionadas ao turismo no município eram desempenhadas pela Diretoria de Turismo e pelas suas coordenadorias, que funcionavam como uma secretaria municipal de turismo.

\subsection{Políticas Públicas Municipais em Turismo}

Os projetos da Diretoria de Turismo de Curitiba são caracterizados pela existência de programas e de um plano que norteia as ações, determinando os objetivos a serem alcançados 
e as estratégias a serem adotadas. Percebe-se que as estratégias apresentadas nesses projetos têm um cunho predominantemente relacionado à oferta. Procurou-se investir em infraestrutura, produtos turísticos, equipamentos e serviços turísticos -, em detrimento das estratégias relacionadas à demanda - que são relacionadas somente às ações de marketing turístico.

A estratégia governamental, com foco na oferta, engloba cerca de $65 \%$ dos projetos. Esse fato aponta para uma significativa preocupação dos dirigentes em prover infra-estrutura, desenvolver produtos e regular os equipamentos e serviços existentes. O projeto de sinalização turística visa reverter os índices de insatisfação do turista com relação a infraestrutura urbana e turística. Apesar de estar pronto para implantação, o referido projeto não foi viabilizado por falta de recursos financeiros para a sua consecução. Os projetos: "Curitiba" "Capital do Natal", "Rotas do Pinhão", "Linhão do Turismo" e "Marcas do Sul do Brasil” são exemplos de investimentos na criação de novos produtos turísticos para o município e representam $45 \%$ do total de projetos relacionados à oferta. Os convênios com universidades contemplam projetos específicos, relacionados à criação de espaços para portadores de necessidades especiais, espaços para eventos, formatação de roteiro histórico-arquitetônico e desenvolvimento de inventários da oferta turística. A preocupação com o padrão de atendimento e as condições dos equipamentos e serviços turísticos prestados pela iniciativa privada de maneira a regular a atividade destacam-se no projeto "Qualidade de Atendimento ao Turista", que contempla treinamento para servidores municipais (guardas municipais e de trânsito), funcionários da rede hoteleira, jornaleiros, frentistas, taxistas, motoristas e cobradores de ônibus. A implantação de postos de informações e pontos de atendimento ao turista complementam os serviços de atendimento. São oito postos de informações turísticas na cidade, com horário de funcionamento diferenciado de acordo com o local onde estão instalados.

Barbosa (2003) ressalta que o enfoque à demanda, numa estratégia governamental, deve ser precedido de uma posição pró-ativa que compreenda o mercado em questão e também aquilo que se tem a oferecer. As ações que derivam dessa estratégia relacionam-se à promoção do destino, à realização de eventos e o monitoramento dos resultados alcançados por meio de pesquisas e estudos estatísticos.

Esse tipo de estratégia é identificado em seis projetos da Diretoria de Turismo, dos quais quatro tem relação direta com a promoção e divulgação de Curitiba como destino turístico: o 
Termo de Cooperação Curitiba- São Paulo, a participação em eventos, a realização de workshops e fampress e a confecção e distribuição de materiais promocionais. A captação de eventos - turísticos, técnico-científicos ou culturais - é um dos projetos de maior interação entre a Diretoria de Turismo e o trade, e que, a curto prazo, é, visivelmente, a melhor solução para minimizar os efeitos da sazonalidade da atividade turística.

\subsection{Recursos Turísticos}

Os recursos turísticos estudados referem-se apenas aos atrativos turísticos naturais e históricoculturais existentes no município pesquisado. A capital do Estado é caracterizada por atrativos construídos pelo homem e que, de certa forma, traduzem o sentimento local. São quarenta e sete atrativos, na sua maioria, históricos e culturais, catalogados pela Diretoria de Turismo e que são considerados de maior expressividade para a cidade. Desses atrativos, somente um é administrado pela Diretoria de Turismo: a Torre Panorâmica, cedida à diretoria pela empresa de telefonia proprietária, por intermédio de um acordo de concessão. Vinte e seis atrativos, em sua maioria parques e bosques, estão sob a supervisão exclusiva da Secretaria Municipal de Meio Ambiente - SEMA, a qual compete a conservação dos prédios, a preservação e a manutenção das áreas verdes.

À Fundação Cultural de Curitiba (FCC) cabe administrar oito atrativos, em sua maioria monumentos, memoriais, prédios e construções relacionados à cultura e à história local. Em conjunto com a SEMA, gerencia ainda quatro outros atrativos, sendo o mais expressivo o conjunto arquitetônico da Ópera de Arame. A URBS - Urbanização de Curitiba S/A é responsável pela Universidade Livre do Meio-Ambiente (UNILIVRE) e também pelas ruas da cidadania, estas últimas são administrada em conjunto com o Instituto de Pesquisa e Planejamento de Curitiba - IPPUC. O Teatro Guaíra e o Museu Oscar Niemeyer - MON pertencem e são gerenciados pelo governo do estado. A Universidade Federal do Paraná - é o único atrativo cuja administração e propriedade é do Governo Federal. A Casa Culpi, que pertence à prefeitura, é administrada pela comunidade de Santa Felicidade, assim como o Bosque São Cristóvão, que também pertence ao bairro. O único atrativo gerido somente pela iniciativa privada é a Ordem Rosa Cruz.

Logo, a ingerência da Diretoria de Turismo sobre os atrativos turísticos da cidade é mínima, uma vez que quase noventa por cento desses atrativos pertencerem à prefeitura municipal. Um problema associado a essa ingerência é a necessidade de estabelecimento de parcerias para 
conservar e preservar esses atrativos. Apesar de não ser diretamente responsável pela manutenção dos atrativos turísticos locais, as reclamações referentes aos atrativos são, em sua maioria, destinadas à Diretoria. Cabe a ela apenas a divulgação desses pontos por meio da folheteria e dos postos de informações turísticas.

\subsection{Recursos Organizacionais}

Os recursos organizacionais da Diretoria de Turismo de Curitiba foram analisados segundo a classificação de Barney (1997) que os subdivide em: recursos de capital humano, financeiros, físicos e institucionais. A articulação de recursos, representada nos recursos institucionais de Barney (1997), foi ressaltado pela inserção do conceito de arquitetura estratégia de Kay (1996).

\section{- Recursos de capital humano}

A Diretoria de Turismo conta em seu quadro com funcionários da CIC, funcionários da prefeitura, cargos em comissão (nomeados) e estagiários, que para alguns gestores podem gerar problemas, principalmente relacionados à qualificação e motivação. Atualmente, são 16 funcionários e mais os estagiários que trabalham nos postos de informações turísticas.

A despeito da necessidade de mão-de-obra qualificada, apontada pelos gestores, existe uma grande dificuldade de conseguir bons estagiários, pois a maioria deles procura por uma melhor remuneração do que a oferecida pela Diretoria de Turismo. Outro problema diz respeito à formação acadêmica dos funcionários. Dos dezesseis funcionários somente dois são Bacharéis em Turismo, além dos estagiários, que ainda estão na graduação. Outra dificuldade com relação a mão de obra: convencer as pessoas de que o turismo necessita de planejamento de mão de obra.

A capacitação de pessoal é vista pelos gestores como um ponto falho na gestão do turismo no município de Curitiba o que ocasiona problemas de qualidade de atendimento ao turista nos postos de informações turísticas. Verificou-se também que os insights dos gestores são de fundamental importância para lidar com a dinamicidade da atividade e que o grande desafio, em relação aos recursos humanos, é convencer o poder público, em especial as esferas superiores, a abraçar a idéia do turismo como atividade econômica viável e sustentável para o município. 


\section{- Recursos financeiros}

As receitas destinadas a conceber os projetos da Diretoria de Turismo são provenientes de diversas fontes: da iniciativa privada -das parcerias realizadas por projeto; da própria CIC que dependem de solicitações e prioridades dentro da companhia; da receita dos ingressos da Torre Panorâmica; de verbas de outras secretarias afins e de receitas provenientes de programas estaduais e federais.

A aplicação desses recursos é feita de acordo com os projetos existentes em cada coordenadoria, obedecendo a seguinte ordem: folheteria (em função dos postos de atendimento), participação em eventos, projetos e treinamento. Quando ocorrem priorizações de projetos, principalmente relacionados à promoção de eventos (ex: Curitiba Capital do Natal), os recursos são realocados para atender às necessidades desse projeto específico. Um fator favorável ao turismo e que, ao mesmo tempo, serve como solução imediata para a escassez de verbas são as parcerias com outras secretarias municipais, principalmente com relação à manutenção dos atrativos turísticos da cidade.

Por intermédio dos gestores, percebeu-se que as dificuldades orçamentárias da Diretoria de Turismo atingem principalmente a execução de projetos referentes à infra-estrutura local e de apoio ao turismo. Ocorre que, para projetos relacionados à promoção e divulgação da cidade e para a captação de eventos, os recursos necessários são supridos pela iniciativa privada, com o estabelecimento de parcerias e patrocínios.

\section{- Recursos físicos}

Segundo o coordenador de promoção, a condição dos equipamentos "é bem razoável, mas poderia ser melhor". A Diretoria de Turismo ocupa dois andares do prédio da CIC localizado na região central de Curitiba. No primeiro andar funcionam a coordenadoria de atendimento e o posto de informações turísticas e, no terceiro, o gabinete do diretor de turismo, a gerência de turismo e as coordenadorias de planejamento e promoção. Apesar de estarem bem instaladas fisicamente, essas duas coordenadorias dividem um mesmo espaço, cada qual de um lado da sala, o que favorece a comunicação entre eles.

Os postos de informações turísticas estão alocados em espaços cedidos, firmados por convênios e parcerias, uma vez que a CIC não possui nenhum imóvel, exceto o prédio em que se localiza a sede da companhia. Isto gera empecilhos burocráticos e prejudica a qualidade de atendimento ao turista, como o exemplificado por um dos gestores: "no posto da rodoviária a 
gente não pode colocar nada lá sem a autorização da URBS. Banners, mapas, tudo a gente tem que pedir a autorização deles”.

\section{- Recursos institucionais}

A Diretoria de Turismo possui uma estrutura bem enxuta, com cinco gestores principais, que ocupam os cargos de diretor, gerente e coordenadores; o que, conforme depoimento dos entrevistados, dinamiza o andamento dos projetos. Esta disposição dos cargos e a formação de grupos de trabalho para execução dos projetos são favoráveis também à comunicação. As relações informais entre os gestores e o bom convívio no dia-a-dia são pontos que reforçam o caráter positivo do relacionamento interno.

Entretanto, a subordinação da "pasta do turismo" a uma companhia de desenvolvimento gera desconforto entre os dirigentes da Diretoria de Turismo. Segundo eles essa falta de independência "gera um problema de identidade do turismo" e "sendo independente seria muito mais dinâmica, com muito mais liberdade de decisões". Estar alocada dentro de uma companhia acarreta a disputa de recursos com outras áreas e outros projetos, mesmo sendo o turismo uma atividade essencial para o desenvolvimento econômico municipal. Problemas oriundos da hierarquia organizacional e da dependência criada na tomada de decisões são advindos dessa condição e dificultam a operarionalização dos projetos relacionados ao turismo.

No entanto, apesar de discordarem dessa sujeição, o fato de estarem inseridos dentro da CIC também traz alguns benefícios. A Diretoria de Turismo tem à sua disposição uma estrutura física com salas, equipamentos e mobiliário, além de funcionários da companhia auxiliando nas tarefas diárias. Os gestores ressaltam ainda que toda a estrutura de apoio da CIC assessoria jurídica, de imprensa, de informações, almoxarifado - é utilizada pela Diretoria de Turismo.

O planejamento da Diretoria de Turismo é subdivido em três áreas, de acordo com as coordenadorias: a promoção turística é responsável pela divulgação da cidade, captação de eventos, realização de workshops e folheteria; o atendimento cuida do disque-turismo, do site, dos postos de informações, da linha turismo e do mailing; e o planejamento turístico desenvolve os convênios com as universidades, realiza o treinamento com os colaboradores da prefeitura e coordena os projetos de captação de recursos. A coordenação e o controle desses projetos são feitos em reuniões periódicas com os gestores de cada coordenadoria. 
- Articulação de recursos (Arquitetura organizacional)

A aproximação da Diretoria de Turismo com outras organizações é elemento chave para que seus projetos sejam viabilizados. O turismo, como ressalta seu dirigente, necessita de todo aparato da prefeitura para funcionar. Seja a Secretaria do Meio-Ambiente, por gerenciar os parques e bosques da cidade; a Fundação Cultural de Curitiba, responsável pelos espaços culturais da cidade; ou da Secretaria de Comunicação, que atualiza o site da Diretoria. O contato entre as secretarias municipais existe e firma-se baseando-se na troca de informações e articulações entre os órgãos. Todos os organismos municipais que recebem turistas, seja por visitas técnicas ou organização de eventos, são vistos pela Diretoria como parceiros. Os gestores destacam que as questões políticas nesse caso pouco afetam, possibilitando o trabalho em conjunto para fazer a atividade turística funcionar de forma satisfatória.

Geralmente, essas parceiras com as organizações do trade envolvem a articulação de recursos financeiros e organizacionais. Hoje, por estar ancorada dentro da CIC, a Diretoria de Turismo beneficia-se de parcerias com empresas localizadas na Cidade Industrial e seu apoio financeiro vem contribuindo, em larga escala, para os projetos de divulgação e promoção da cidade. Entretanto, essas parcerias com a iniciativa privada ainda estão amadurecendo. Os gestores públicos afirmam que tem havido um grande esforço de ambas as partes para se trabalhar de forma integrada, tentando fortalecer o turismo na cidade e construindo uma imagem da cidade como destino turístico. Com o setor público, as parcerias abrangem os três níveis governamentais: municípios, o estado e a federação e são efetivados por intermédio de articulação de recursos nos projetos. A cooperação com outros municípios geralmente privilegia o recurso institucional e, nesses casos, o bom relacionamento externo é a primeira e principal condição para consolidar as parcerias com outras secretarias de turismo.

O trabalho em conjunto com o Estado sofreu grande influência de fatores políticos nos dois últimos anos, em que a representação política partidária do Estado divergia da existente no município. Essas diferenças políticas, de acordo com os dirigentes da Diretoria de Turismo, atrapalharam bastante as parcerias na disponibilização de recursos financeiros e atenção aos problemas do turismo no município. Entretanto, em relação à participação em eventos, apoio institucional, pesquisas e manutenção dos postos de atendimento, as diferenças políticas não afetaram significativamente, até porque, conforme o coordenador de promoção, no momento da escolha do destino, "o turista não quer saber o que é Estado e o que é Município, para ele não interessa a questão política". 
Para as parcerias com o governo federal era necessário que os projetos encaminhados ao Ministério do Turismo se encaixassem nas diretrizes determinadas pela política nacional, entretanto, mesmo que esse pré-requisito fosse atendido, havia a questão da Diretoria de Turismo ser parte de uma companhia de economia mista e, portanto, estar impedida de receber recursos federais. Esses dois aspectos tolheram-na de utilizar verbas governamentais para realizar certos projetos, mas não inviabilizaram a participação do ministério e da EMBRATUR na atividade turística do município. Os dirigentes ressaltaram que independentemente das receitas para os projetos, sempre houve o apoio institucional o que, na visão deles, é o fator preponderante na formação de parcerias com o setor público e, principalmente, é o papel dos órgãos de turismo federais.

\subsection{A Percepção dos Gestores do Setor Privado}

Os gestores privados têm uma percepção muito particular sobre a gestão que o município deveria desempenhar e as funções que estão sendo realizadas no âmbito da atividade turística local. Alguns creditam ao município o dever de zelar pela infra-estrutura e manutenção dos atrativos turísticos, outros enfatizam que, além do foco no desenvolvimento de políticas públicas voltadas à infra-estrutura da cidade, deve-se, também, atentar para a qualidade de atendimento prestado aos turistas, por intermédio de treinamentos, cursos de reciclagem, capacitação e sensibilização dos envolvidos com a atividade.

Uma visão interessante foi ponderada em relação aos incentivos ao setor e a definição do papel do poder público como motivador da indústria do turismo. Conforme o depoimento de um dos dirigentes, há necessidade de o município assumir a responsabilidade de criar o interesse do trade em investir no turismo: "fazer com que as pessoas acreditem na necessidade de existência do turismo". Contudo, alguns gestores do setor privado afirmam que o próprio poder público repudia, ou ignora, a importância do turismo para a economia local.

Observa-se certa tendência por parte dos gestores privados em enumerar diversos problemas quando indagados sobre como o município está intervindo na exploração dos atrativos turísticos locais e na promoção de Curitiba como um destino turístico. Destaca-se, entre esses problemas, a questão da não existência de uma secretaria ou órgão independente para gerir o turismo e o planejamento de ações de incentivo para a atividade. 
De forma geral, as organizações privadas preconizam a parceira com o município como sendo de extrema valia e necessária para que a cidade possa ser promovida como destino turístico. A participação do setor privado na atividade turística é destacada pela importância das empresas como canal primeiro de recepção do turista. Seja em suas acomodações, nos traslados ou nas refeições servidas a atuação da iniciativa privada é imprescindível. Entretanto, há um desconforto visível entre os dirigentes privados quando indagados das vantagens (leia-se lucratividade e rentabilidade) que o turismo poderá gerar em seus empreendimentos. Isso retrata de certa maneira a dificuldade de entendimento entre os interesses públicos e privados quanto ao rumo da atividade turística local.

\section{Conclusões e Considerações Finais}

A presença e a significância dos municípios vêm se intensificando na esfera nacional a partir das iniciativas do governo federal de descentralização da gestão do turismo e da crescente demanda por soluções locais para o desenvolvimento dos municípios. Assim, a clara definição das responsabilidades e dos benefícios advindos pelo turismo e o estabelecimento do papel de cada ator nesse processo de desenvolvimento são de fundamental importância para a consolidação econômica da atividade.

Analisando os recursos que influenciam a gestão pública do turismo, verificou-se que o que se destaca como principal diferencial para a Diretoria de Turismo de Curitiba é o recurso institucional. Identificou-se ainda que, a presença do planejamento e uma cultura interna voltada para uma visão empresarial da gestão pública do turismo, determinam o que se pode denominar cultura empresarial no meio público.

Os recursos turísticos, apesar de não serem citados como recursos relevantes para a formulação e implementação de políticas públicas, são os principais recursos disponíveis à cidade para divulgar o turismo. A existência de atrativos turísticos singulares é indispensável para a exploração do turismo de lazer e também complementa a promoção de Curitiba como um destino turístico de negócios e eventos. Pode-se destacar que a articulação de recursos, representada pela arquitetura organizacional é também o ponto forte da gestão pública do turismo em Curitiba. Dois pontos salientam essa assertiva: primeiro, a utilização desse recurso em diversos projetos da Diretoria de Turismo e segundo, a sua importância atribuída pelos gestores. 
Constatou-se também que, ainda que as parcerias se destaquem como instrumentos recorrentes aos projetos, a articulação de recursos deve ser eleita como foco para o turismo em Curitiba, visando desonerar algumas ações do poder público mas, principalmente, no intuito de incentivar a participação de todos os beneficiados no processo. Isso posto, identificou-se que um dos maiores problemas para o desenvolvimento do turismo de Curitiba é, exatamente, a articulação de recursos. O estabelecimento de parcerias com a iniciativa privada ainda é incipiente e refere-se, em sua maioria, à disponibilização de recursos financeiros, não explorando a existência de outros recursos que poderiam ser compartilhados. Com o setor público, a realidade do trabalho em conjunto não é diferente, pois a maioria das parcerias está em fase de amadurecimento ou esbarra em aspectos políticos antes que possam ser concretizada.

No contexto em que a participação efetiva do setor público (municipal, estadual, federal) e da iniciativa privada é necessária para a atividade turística, verificou-se em Curitiba a necessidade de um envolvimento efetivo entre todos os atores do processo, incluindo também a comunidade, de forma a entrosar esses atores e fazendo com que participem e contribuam no processo de mudanças. Logo, a participação de cada organização pode ser hipoteticamente dividida, cabendo ao setor público a parcela de incentivo e provimento de infra-estrutura turística e à iniciativa privada o fornecimento de equipamentos e serviços de qualidade.

Cabe destacar nos depoimentos um grande interesse dos gestores municipais de Curitiba em ter e, principalmente, em manter políticas para o turismo, não só em relação à captação de recursos, mas também como forma de se determinar os objetivos e metas a serem alcançados. A política, neste caso, seria utilizada como um norteador para a atividade local e um eficaz instrumento de aferição das ações do poder público em busca do desenvolvimento do turismo no município.

\section{Referências Bibliográficas}

BARBOSA, L. G. 2003. Políticas públicas para o desenvolvimento do turismo: o caso do município de Rio das Ostras. Observatório de inovação do turismo. Disponível em: < http://www.embratur.gov.br/0-catalogo-documentos/observatorio/

PolíticasPublicasparaoDesenvolvimentodoTurismo.pdf.> Acesso em: 20 fev 2003.

BARNEY, J. 1997. Gaining and sustaning competitive advantage. Reading - MA: Addison Wesley. 1996. The resource-based theory of the firm. Organization Science. v. 7, n. 5. 
CARNEIRO, J. M. T.; CAVALCANTI, M. A. F. D.; SILVA, J. F. da. 1999. Os determinantes da sustentabilidade da vantagem competitiva na visão resource-based. In: Anais do Encontro da ANPAD, 23, 1999, Foz do Iguaçu. 1 CD-ROM.

DAFT, R. 1983. Organization theory and design. New York: west.

EMBRATUR. S/D. Artigos selecionados. Disponível em: <http://www.embratur.gov.br $>$. Acesso em 05 jul. 2004.

FÓRUM PARA O TURISMO SUSTENTÁVEL NO PARANÁ. 2004. Os números do turismo no mundo, no Brasil e no Paraná. Curitiba: SEBRAE/PR.

GIL, A. C. 1991. Como elaborar projetos de pesquisa. 3. ed. São Paulo: Atlas.

GRANT, R. M. 1991. The resource-based theory of competitive advantage: implications for strategy formulation. In: California Management Review. v. 33, n. 3, p. 114-135.

KAY, J. 1996. Fundamentos do sucesso empresarial: como as estratégias de negócios agregam valor. Rio Janeiro: Campus.

LICKORISH, L. J.; JENKINS, C. L. 2000. Introdução ao turismo. Rio de Janeiro: Campus.

LEE, G. P.; BARRETT, G. W. 1994. EC support for tourism in ACP states and regions: implications for the public and private sectors. In: Tourism Management. v.15, n. 3, p. 200-202.

MASCARENHAS, A. O.; VASCONCELOS, F. C de. 2004. Tecnologia na gestão de pessoas: estratégias de auto-atendimento para o novo RH. São Paulo: Pioneira Thomson Learning.

MINTZBERG, H; AHLSTRAND, B. W.; LAMPEL, J. 2000. Safari de estratégia: um roteiro pela selva do planejamento estratégico. Porto Alegre: Bookman.

PEARCE, D. G. 1998. Tourism development in Paris: public intervention. In: Annals of Tourism Research. v. 25, n. 2, p. 457-476.

PENROSE, E. 1995. Theory of the growth of the firm. Oxford: Oxford University Press, $3^{\text {rd }}$. ed.

SELZNICK, P. 1957. Leadership in administration. New York: Harper \& Row.

SECRETARIA DE ESTADO DO TURISMO DO ESTADO DO PARANÁ- SETU. 2003. Política estadual de turismo 2003-2007. Curitiba.

WERNERFELT, B. 1984. A resource based-view of the firm. In: Strategic Management Journal. v. 5, p. $171-180$.

\section{Recebido em: 8/10/2005 ( $1^{\mathrm{a}}$ versão) $23 / 01 / 2006$ ( $2^{\mathrm{a}}$ versão) Aprovado em: 9/02/2006}

